\title{
INVESTIGATION OF EFFECT OF PHOSPHOLIPIDS ON PHYSICAL AND FUNCTIONAL CHARACTERIZATION OF PACLITAXEL LIPOSOMES
}

\author{
AMOL A. TATODE ${ }^{*}$, ARUN T. PATIL ${ }^{2}$, MILIND J. UMEKAR ${ }^{2}$, DARSHAN R. TELANGE ${ }^{2}$ \\ 1Department of Pharmaceutics, University Department of Pharmaceutical Sciences, Rashtrasant Tukadoji Maharaj Nagpur University, \\ Nagpur, Maharashtra 440033, India, ${ }^{2}$ Kishoritai Bhoyar College of Pharmacy, Kamptee, Nagpur, Maharashtra 441002, India
}

Email: aatatode@rediffmail.com

Received: 16 Jun 2017 Revised and Accepted: 02 Nov 2017

\begin{abstract}
Objective: Aim of the present investigation was to determine the effect of various synthetic grades of phospholipids on paclitaxel liposomes (PTL).

Methods: The PTL formulations using various grades of phospholipids were prepared by film hydration method. The prepared PTL formulations were physicochemically characterized by entrapment efficiency (EE, \%w/w), vesicular size and particle size distribution. These formulations were also characterized for function parameters such as in vitro release and hemolytic toxicity assay.

Results: The synthetic grades of phospholipids significantly influenced PTL formulations. The stoichiometric ratio (1:1) between $\mathrm{CH}$ and various synthetic phospholipids was found to be optimized one, from rest of the ratios. The characterization confirmed the formation of PTL. The EE was observed to be high (86.67\%) as increasing the ratios between $\mathrm{CH}$ and phospholipids but then declined suddenly as further increasing the ratio. The best liposomal formulations showed that the spherical shape was found to be within size ranging from $<10 \mu \mathrm{m}$, with a higher rate and extent of the release, $\sim 86.22 \%$ of paclitaxel from PTL formulation. The results of the hemolytic toxicity study demonstrated that PTL formulations with a ratio (1:1) exhibited a significantly lower hemolytic toxicity (2.70\%), compared to all formulations.
\end{abstract}

Conclusion: The result revealed the excellent effect of phospholipids on paclitaxel liposomes. The paclitaxel liposomes prepared with CH: PL90G ratio (1:1) was found to be optimized one. The entrapment efficiency, particle size distribution, in vitro release and hemolytic activity with this ratio shown to be excellent as compared to other ratios.

Keywords: Liposomes, Phospholipon, Entrapment efficiency, In vitro release, Hemolytic toxicity

(C) 2017 The Authors. Published by Innovare Academic Sciences Pvt Ltd. This is an open access article under the CC BY license (http://creativecommons.org/licenses/by/4.0/) DOI: http://dx.doi.org/10.22159/ijpps.2017v9i12.20749

\section{INTRODUCTION}

Cancer is a challenging and complex disease causes most of the population around the world. Where the normal cell physiology altered totally and directs to malignant tumors. These unwanted tumor growth cells during their journey (normal cell conversion to abnormal cell) affect the neighbouring and dissimilar cells, results in the death of the cancer patient [1]. On the basis of previous history and research, the output shows that the prolonged exposure of virus attack, chemicals, inflammation, radiation and proactive agents could be responsible for the initiation of this disease. Moreover, in the changes of normal cell physiology, following modifications might be accountable, i.e. growing and signalling of tumor cells in a selfsufficient way, showing insensitivity to a tumor growing cells, unlimited replication and finally, the metastasis [2]. Over the last three decades, the extensive research has been going on this metabolic disorder in order to understand its process, mechanism, and transformation from normal growth to unwanted tumor growth cells. The synthetic anticancer agents can be helpful in treating cancer; however, prolonged exposure, accompanied by a heavy dose of these agents could be caused inconvenience to normal cells [3].

The natural origin based anticancer agent like paclitaxel (PT), isolated from the bark of Taxus brevifolia (northwest Pacific Yew tree), characterized it as a white crystalline powder, with the empirical formula $\left(\mathrm{C}_{47} \mathrm{H}_{51} \mathrm{NO}_{14}\right)$ and on the basis of characterization named it as Taxol. Later on, the Bristol-Myers Squibb Company developed this isolated compound commercially with the generic name Paclitaxel and then sold under the trademark Taxol. As per as anticancer activity is concerned, PT exclusively binds to the $\beta$ tubulin subunit through $\mathrm{N}$-terminal side chain with 31 amino acid, in the microtubules [4-5] causing depolymerization of $\beta$-tubulin subunit, with inhibition of mitosis and this combined effect can be directed to induction of cell apoptosis [6]. Based on previous reports, PT shows anticancer activities towards breast cancer [7], ovarian cancer [8], lung cancer [9] and pancreatic cancer [10]. Supportive to this, previously published reports by Mullins et al. [11], shows that PT gives antitumor activity by a formation of macrophage IL-12 through nitric oxide, which further caused to dysregulation of IL-12 p40 expression and finally reduces the tumor growth. Additionally, PT also exhibits anticancer activity by removing phosphofructokinase from melanoma cells, accompanied by reducing the level of glucose and fructose 1,6-phosphatase, with ATP [12].

PT possesses such wide spectrum anticancer potential. However, PT exhibits poor aqueous solubility and permeability owing to biopharmaceutical classification system (BCS) class IV drug, which directs it to low bioavailability. Moreover, the low bioavailability could be caused by following reasons; a) PT, an efficient anticancer drug act as substrate for drug efflux pump transporter i.e. Pglycoprotein (P-gp) and multidrug resistance protein (MRP-2), these P-gp and MRP-2 with substrate, inhibits oral absorption of PT by excreting it into intestinal lumen $[8,13]$, b) PT follows the widespread pre-systemic first pass metabolism in liver and gut by involvement of cytochrome enzymes (CYP3A and CYP2C8) $[8,14]$. C) Lower elimination half-life $(t 1 / 2 e l)[15]$. Therefore, by consideration of these problems, there is a need to develop a novel formulation of such effective and efficient anticancer drug.

For improving poor aqueous solubility and permeability of PT, a number of formulation strategies have been developed and used. Some of them were modified, due to some excipient-drug interactions. For improving the solubility, PT dissolved in a mixture of polyoxyethylated castor oil (Cremophore EL): dehydrated ethanol (1:1) ratio as a delivery vehicle. The formulation produced hypersensitivity and non-linear pharmacokinetic behaviour after intravenous administration. The hypersensitivity reaction at the site of administration could be due to an inclusion of Cremophore EL [16-17]. After that, the delivery vehicle was replaced with the 
addition of tween 80 alone or combination of tween 80: dehydrated alcohol, and diluted with aqueous media. The diluted formulation showed the precipitation of PT from solution due to low solubility [18]. These attempted techniques, with a persistent low solubility problem, have been overcome by creating novel formulation with the aim of improving aqueous solubility, permeability, and bioavailability of PT. It includes novel oral formulation [19], novel PT self-emulsifying drug delivery system (SEDDS) [20], novel ligands based PT targeting formulation [21], micellar formulation [22], liposomal formulation [23], bioconjugates [24], dendrimers [25], and microspheres [26]. In all these formulation techniques the problem associated with PT was shown to be improved significantly.

The liposome is emerging techniques for specialized drug delivery [27] and best suitable for lipophilic drug due to its biocompatibility and reducing drug toxicity, with maintaining the efficacy of the anticancer drug for a maximum period of time. Some previous studies include asulacrine [28], docetaxel [29], tamoxifen [30] and temozolomide [31] with these approaches, their poor aqueous solubility and bioavailability were found to be improved. Therefore, the present work was aimed to formulate and characterize the paclitaxel liposomes (PTL) using synthetic phospholipids for topical drug delivery and studied their effect on vesicle size, drug entrapment and in vitro release of PT. Moreover, the PTL was also characterized and investigated for hemolytic toxicity assay.

\section{MATERIALS AND METHODS}

\section{Materials}

Paclitaxel (PT), (purity $>90 \%$ ) was received as a gift sample from MAC-CHEM Products (India) Pvt. Ltd. Bhoisar, Thane, India. The phospholipids samples viz., Phospholipon 90G ${ }^{\circledR}$ (PL90G), Phospholipon $80 \mathrm{H}^{\circledR}$ (PL80H) and Phospholipon $90 \mathrm{H}^{\circledR}(\mathrm{PL90H})$ with purity $>90 \%$, was obtained as a free gift sample from Lipoid GmbH, Ludwigshafen, Germany. The solvent namely acetonitrile, chloroform, and methanol were purchased from Merck Ltd. Mumbai, India. Cholesterol $(\mathrm{CH})$, potassium dihydrogen phosphate and sodium hydroxide pellets were obtained from Sigma Chemicals, Sigma-Aldrich Corporation, St. Louis, MO. A chemical used in this work were of analytical grade (AR).

\section{Preparation of paclitaxel liposomes (PTL)}

PTL's were prepared according to the previously reported procedure described by Dua [32]. Briefly, the $\mathrm{CH}$ and phospholipids (i.e. CH: PL90G, CH: PL80H and CH: PL90H) at various stoichiometric ratios of $(1: 0.25,1: 0.5,1: 1,1: 2$ and 1:3) accompanied with PT was accurately weighed and placed into $100 \mathrm{ml}$ round bottom flask. The weighed ingredients were dissolved in $10 \mathrm{ml}$ of chloroform. The round bottom flask was then fixed to Rotary vacuum evaporator (Model: PBV-7D, Vertical condenser, Rotavap, Superfit ${ }^{\mathrm{TM}}$ Continental Pvt. Ltd., Mumbai, India) at an inclined position and temperature of the flask was kept constant at $40{ }^{\circ} \mathrm{C}$ using the water bath for three hours. The organic solvent was evaporated under reduced pressure and a thin film was obtained. The obtained thin film was hydrated by the addition of $30 \mathrm{ml}$ of phosphate buffer ( $\mathrm{pH} \mathrm{7.4)}$ and vortexed for $15 \mathrm{~min}$. After vortexing, the whole liposomal formulation was centrifuged at 20,000 rpm for $45 \mathrm{~min}$ and separated the supernatant part that contains free (non-incorporated) PT. The settled sediment containing PT were further redispersed into phosphate buffer $(\mathrm{pH}$ 7.4) up to $25 \mathrm{ml}$ in order to achieve a lipid content of $1 \mathrm{mg} / \mathrm{ml}$ and then transferred to an amber color glass vial and stored at $4{ }^{\circ} \mathrm{C}$. The formulation batches for PTL using a different ratio of $\mathrm{CH}$ and phospholipids viz., PL90G, PL80H, and PL90H are shown in table 1.

\section{Characterization of PTL}

\section{Entrapment efficiency}

The entrapment efficiency (EE) is defined as the ratio of the amount of the PT encapsulated in the liposome to that of the total PTL dispersion. The amount of PT encapsulated in liposomes was measured by using the ultracentrifugation method [33]. Briefly, the $2 \mathrm{ml}$ of PTL dispersion was placed into $10 \mathrm{ml}$ of volumetric flask and diluted up to the mark with a mixture of acetonitrile: phosphate buffer (pH 7.4) and then sonicated. After complete disruption of PTL vesicles, the reaction mixture was centrifuged at $10,000 \mathrm{rpm}$ for 5 min to separate the supernatant. The collected supernatant was suitably diluted and the absorbance of the resulting solution was recorded at $217 \mathrm{~nm}$ using UV-visible spectrophotometer (Model: SPECTRO 2060 PLUS, Analytical Technologies Ltd., Gujarat, India).

\section{Vesicular size and distribution}

Motic Digital Microscope (type DM-1802) was used to characterize the vesicles size and size distribution of PTL. Briefly, $2 \mathrm{ml}$ of PTL dispersion was placed over the clean slide and covered with a coverslip. The microscopic characterization of PTL was examined at the magnification of $(\times 40)$ using calibrated eyepiece micrometer. The images were recorded using Motic Image Plus 2.0 ML software, accompanying with the instrument.

\section{In vitro release study}

The in vitro release study for PT from PTL formulation was carried out as per the procedure described by Utreja [34] with little modifications. In brief, the Franz diffusion cell apparatus was employed for this study. The apparatus consists of donor and receptor compartment, with an effective surface area for dissolution was $\left(2.303 \mathrm{~cm}^{2}\right)$. The dialysis membrane (LA395, Dialysis Membrane-110 AV, flat width $\sim 31.12 \mathrm{~mm}$, Average diameter $\sim 21.5$ $\mathrm{mm}$, and approximate capacity is $\sim 3.63 \mathrm{ml} / \mathrm{cm}$; Himedia laboratories, Mumbai, India) were employed and pre-treated as per the directions were given by the manufacturer. After proper pretreatment, the membrane was cut into desired size and shape, then mounted between the effective surface area of donor and receptor compartment. The PTL dispersion $(2 \mathrm{ml})$ was placed over the membrane, accompanied by the addition of phosphate buffer $(20 \mathrm{ml}$, $\mathrm{pH}$ 7.4) as dissolution media in the receptor compartment. The contents of the receptor compartment were stirred at $100 \mathrm{rpm}$ using a magnetic stirrer at $37 \pm 1.0^{\circ} \mathrm{C}$. At specified time intervals, $2 \mathrm{ml}$ aliquots were withdrawn from the sampling port of apparatus, diluted suitably with fresh media and the absorbance of the resulting solution was read at $217 \mathrm{~nm}$ using UV-visible spectrophotometer (Model: SPECTRO 2060 PLUS, Analytical Technologies Ltd., Gujarat, India).

\section{Hemolytic toxicity assay}

The hemolytic toxicity for prepared PTL dispersion was estimated by means of Red Blood Cell (RBC) lysis assay procedure as described by Utreja and Reed et al. [34-35]. Briefly, the prepared PTL dispersion was diluted with phosphate buffer saline (PBS, $2.5 \mathrm{ml}, \mathrm{pH}$ 7.4) to the suitable concentration range. The blood samples were obtained from the tail vein of albino rats, then centrifuged at 3000 rpm for $10 \mathrm{~min}$ and discarded the supernatant part. Then, the settled sediment of the RBC suspension was further diluted with normal saline solution $(0.9 \% \mathrm{w} / \mathrm{v})$ to get concentration up to $5 \% \mathrm{w} / \mathrm{v}$. From this solution, $0.5 \mathrm{ml}$ suspension was mixed with distilled water and then incubated at $37^{\circ} \mathrm{C}$ for $1 \mathrm{~h}$ to get complete $(100 \%)$ hemolysis. After incubation, the contents were centrifuged and separated the supernatant (containing non-lyses RBC). The aliquot of supernatant was diluted with the same quantity of phosphate buffer saline (PBS, $20.5 \mathrm{ml}, \mathrm{pH} \mathrm{7.4)}$ and measured the absorbance of the resulting solution at $540 \mathrm{~nm}$ using UV-visible spectrophotometer (Model: SPECTRO 2060 PLUS, Analytical Technologies Ltd., Gujarat, India) by taking the supernatant normal saline solution as blank. The hemolytic activity of each sample was expressed as \% hemolysis by taking the absorbance of distilled water as $100 \%$ hemolytic sample.

\section{RESULTS AND DISCUSSION}

\section{Entrapment efficiency}

According to previously published reports shows that mainly $\mathrm{CH}$ and phospholipids are employed in different concentration, molar and stoichiometric ratios for the formulation of liposomes [36]. So in the current study, the PTL's were formulated using stoichiometric ratio and also studied the effect of various phospholipids at different concentrations on EE. It is observed that the EE i.e. highest incorporation of PT in liposomal vesicles was found to be enhanced by increasing the ratios between $\mathrm{CH}$ and phospholipids, but then declined suddenly as further increasing the ratio. The obtained 
results (table 1) demonstrated that, by using PL90G, PL80H and PL90H the EE were found approximately $86.67,74.58$ and $80.62 \%$ at 1:1 ratio of $\mathrm{CH}: \mathrm{PL}$

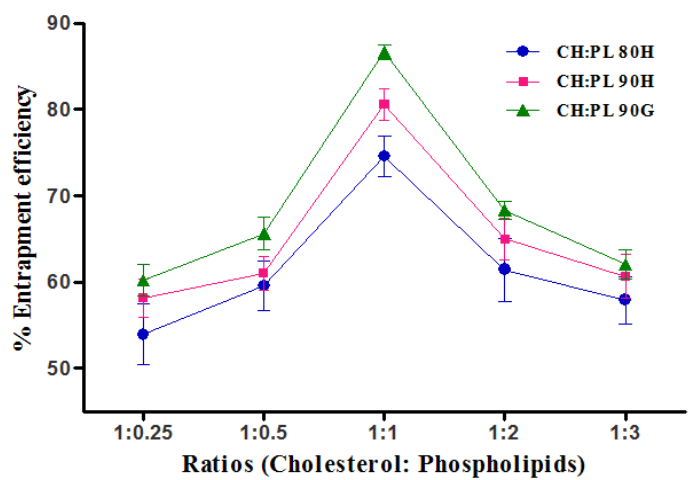

Fig. 1: \% Entrapment efficiency for PTL containing the different ratio of cholesterol and phospholipid. (Results are expressed as mean $\pm S D, n=3$ )

The results were consistent with previously published reports [37]. Thus, it can be concluded that a stoichiometric ratio between $\mathrm{CH}$ and phospholipids, in addition to the selection of proper phospholipids with highest phosphatidylcholine content, might be responsible for obtaining highest EE.

\section{Vesicular size and distribution}

As shown in fig. 2, the surface morphology of PTL was observed by Motic Digital Microscope (type DM-1802). The liposomes were spherical in shape with a smooth surface, size was appropriate and uniform $(\mathrm{CH}$ : PL90G). Fig. 3, shows the average vesicular size and fig. 4, shows the size distribution of PTL prepared with varying ratio of CH: PL. The average vesicular size of PTL prepared with a varying ratio of CH: PL90G, CH: PL80H and CH: PL90H was found to be in the range of $2.96 \pm 0.2955 \mu \mathrm{m}$, $2.83 \pm 0.323 \mu \mathrm{m}$ and $3.18 \pm 0.222 \mu \mathrm{m}$ respectively.

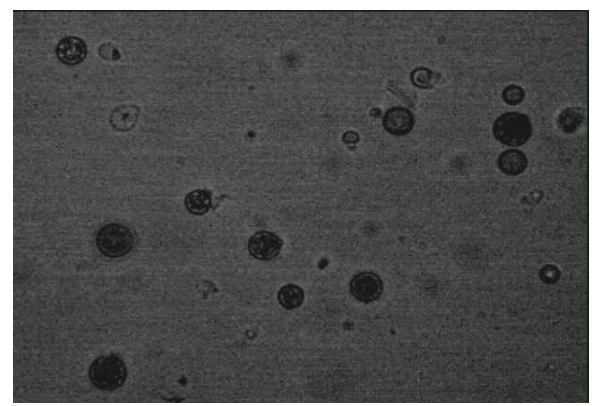

Fig. 2: Microphotograph of PTL by motic image plus 2.0 ML software

Table 1: Composition and characterizations of PTL

\begin{tabular}{|c|c|c|c|c|c|c|c|c|c|c|}
\hline \multirow{2}{*}{$\begin{array}{l}\text { Formulation } \\
\text { code }\end{array}$} & \multirow{2}{*}{$\begin{array}{l}\text { Ratio } \\
\text { (CH:PL) }\end{array}$} & \multicolumn{3}{|c|}{ PL (mg) } & \multirow{2}{*}{$\begin{array}{l}\text { CH } \\
\text { (mg) }\end{array}$} & \multirow{2}{*}{$\begin{array}{l}\text { Drug } \\
\text { (mg) }\end{array}$} & \multirow[t]{2}{*}{$\mathrm{EE}^{*}(\%)$} & \multirow{2}{*}{$\begin{array}{l}\text { Avg. VS \# } \\
(\mu \mathrm{m})\end{array}$} & \multirow{2}{*}{$\begin{array}{l}\text { In vitro release* } \\
(\%)\end{array}$} & \multirow[t]{2}{*}{ HTA* } \\
\hline & & 90G & $80 \mathrm{H}$ & $90 \mathrm{H}$ & & & & & & \\
\hline L1-90G & $1: 0.25$ & 19 & & & 75 & 2 & $60.21 \pm 1.8$ & $3.18 \pm 0.9$ & $62.59 \pm 1.8$ & $5.93 \pm 0.8$ \\
\hline L2-90G & $1: 0.5$ & 38 & & & 75 & 2 & $65.62 \pm 1.9$ & $3.21 \pm 1.0$ & $76.92 \pm 0.9$ & $4.02 \pm 0.8$ \\
\hline L3-90G & $1: 1$ & 75 & & & 75 & 2 & $86.67 \pm 0.9$ & $2.52 \pm 0.9$ & $86.22 \pm 2.0$ & $2.70 \pm 0.5$ \\
\hline L4-90G & $1: 2$ & 150 & & & 75 & 2 & $68.33 \pm 1.0$ & $2.81 \pm 1.1$ & $64.79 \pm 1.2$ & $4.66 \pm 0.7$ \\
\hline L5-90G & $1: 3$ & 225 & & & 75 & 2 & $62.08 \pm 1.7$ & $3.11 \pm 1.0$ & $60.38 \pm 2.1$ & $7.62 \pm 0.6$ \\
\hline L6-80H & $1: 0.25$ & & 19 & & 75 & 2 & $53.96 \pm 3.6$ & $2.99 \pm 1.1$ & $58.11 \pm 1.8$ & $8.60 \pm 1.4$ \\
\hline L7-80H & $1: 0.5$ & & 38 & & 75 & 2 & $59.58 \pm 2.9$ & $2.85 \pm 1.3$ & $65.53 \pm 2.3$ & $7.83 \pm 1.4$ \\
\hline L8-80H & $1: 1$ & & 75 & & 75 & 2 & $74.58 \pm 2.3$ & $2.31 \pm 0.7$ & $79.25 \pm 3.2$ & $6.77 \pm 0.8$ \\
\hline L9-80H & $1: 2$ & & 150 & & 75 & 2 & $61.46 \pm 3.7$ & $2.86 \pm 1.4$ & $62.45 \pm 1.8$ & $7.41 \pm 1.1$ \\
\hline L10-80H & $1: 3$ & & 225 & & 75 & 2 & $57.92 \pm 2.7$ & $3.18 \pm 1.0$ & $53.71 \pm 2.1$ & $9.53 \pm 0.8$ \\
\hline L11-90H & $1: 0.25$ & & & 19 & 75 & 2 & $58.12 \pm 2.2$ & $3.92 \pm 1.1$ & $60.69 \pm 0.7$ & $8.47 \pm 1.0$ \\
\hline L12-90H & $1: 0.5$ & & & 38 & 75 & 2 & $61.04 \pm 1.9$ & $3.03 \pm 0.9$ & $70.88 \pm 1.1$ & $7.21 \pm 1.3$ \\
\hline L13-90H & $1: 1$ & & & 75 & 75 & 2 & $80.62 \pm 1.8$ & $3.18 \pm 1.0$ & $82.64 \pm 0.8$ & $4.44 \pm 0.5$ \\
\hline L14-90H & $1: 2$ & & & 150 & 75 & 2 & $65.00 \pm 2.4$ & $3.49 \pm 1.0$ & $61.70 \pm 2.6$ & $11.01 \pm 0.8$ \\
\hline L15-90H & $1: 3$ & & & 225 & 75 & 2 & $60.63 \pm 2.5$ & $2.92 \pm 0.8$ & $57.23 \pm 3.1$ & $7.83 \pm 0.8$ \\
\hline
\end{tabular}

*Values represented as mean $\pm \mathrm{SD}(n=3)$; \# Values represented as mean $\pm \mathrm{SD}(n=20), \mathrm{CH}=$ cholesterol, PL=phospholipon (PL90G=phospholipon $90 \mathrm{G}^{\circledR}$, $\mathrm{PL80H}=$ phospholipon $80 \mathrm{H}^{\circledR}$; $\mathrm{PL} 90 \mathrm{H}=$ phospholipon $\left.90 \mathrm{H}^{\circledR}\right)$, $\mathrm{CH}$ : PL= paclitaxel liposomes containing different concentrations of phospholipids, EE= entrapment efficiency; VS= vesicular size; HTA= hemolytic toxicity assay.

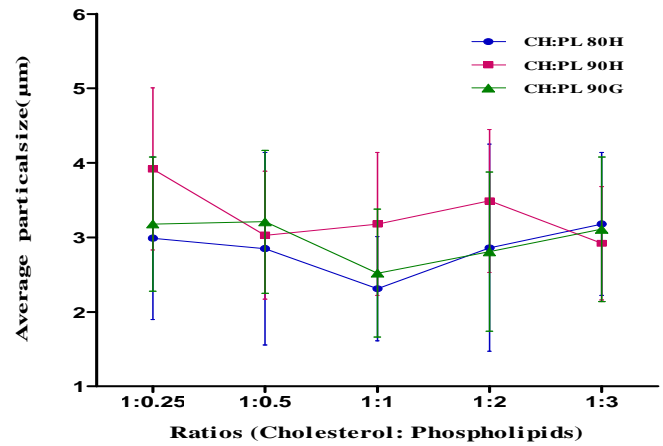

Fig. 3: Average vesicular size of PTL containing different ratios of $\mathrm{CH}$ : $\mathrm{PL}$ (results are expressed as mean \pm SD, $n=20$ )

The results are presented in table 1 . As clearly seen the size distribution $(72 \%)$ was in the range of $2.1-4.0 \mu \mathrm{m}$ for $\mathrm{CH}$ : PL90G,
(97\%) was in the range of $1.1-5.0 \mu \mathrm{m}$ for $\mathrm{CH}$ : PL80H and (87\%) was in the range of 2.1-5.0 $\mu \mathrm{m}$ for $\mathrm{CH}$ : PL90H. 

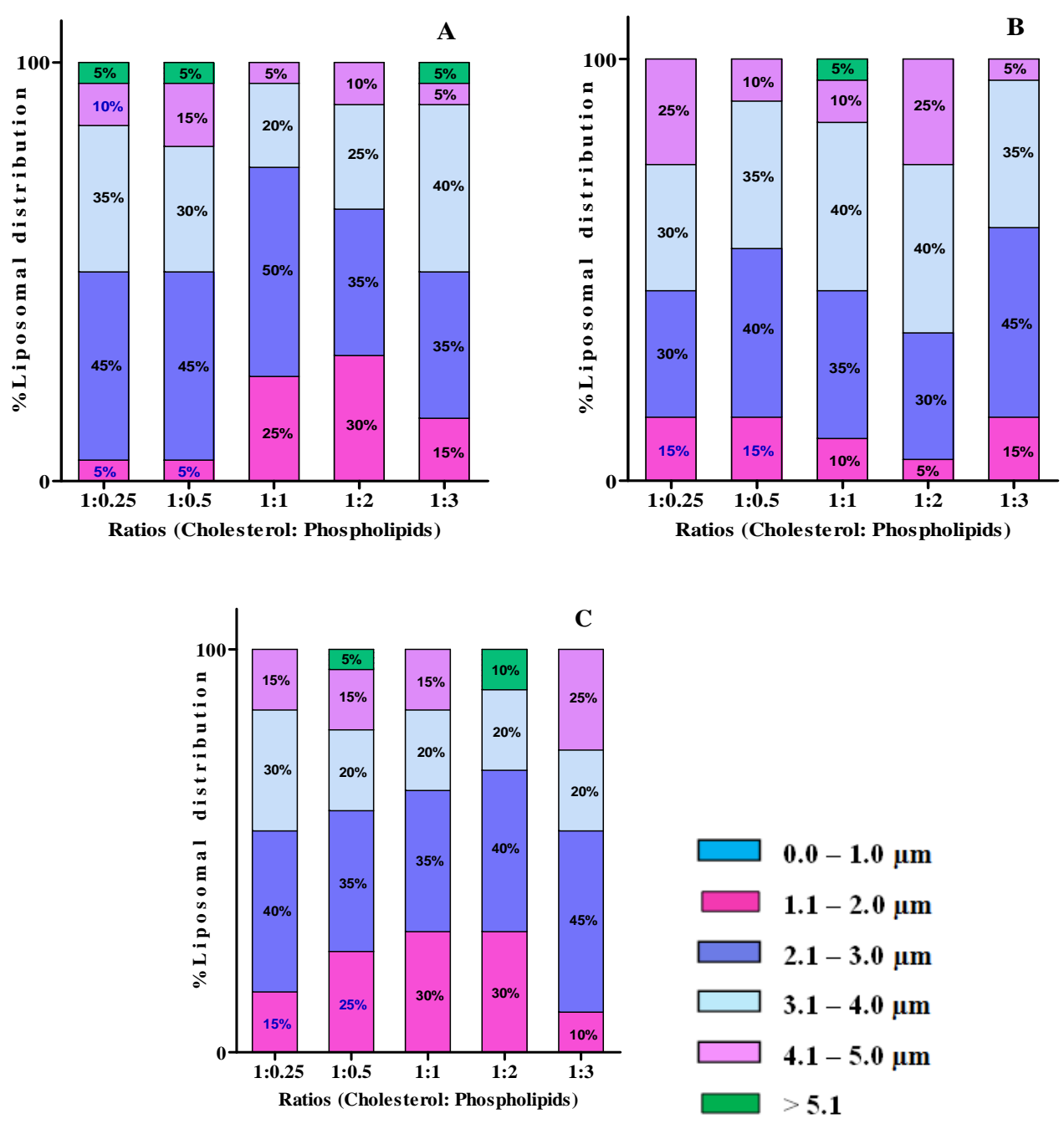

Fig. 4: Percentage (\%) vesicular size distribution of PTL containing different ratios of CH: PL (A= CH: PL90 G; B= CH: PL90H; C=CH: PL80H) (results are expressed as \% distribution out of 20 vesicles)

On the basis of consideration of above results, it suggests that PTL with CH: PL ratio (1:1) demonstrated a smaller vesicle size and $\mathrm{CH}$ : PL90G shows greater uniformity in vesicle size as compared to $\mathrm{CH}$ : PL80H and CH: PL90H. Vesicle size and vesicle size distribution play an important role with respect to permeation and retention in tumor cells and the results of present study are in line with the previous study of Parikh (31).

\section{In vitro release study}

The release of PT from PTL in phosphate buffer saline (PBS, pH 7.4, $20 \mathrm{ml}$ ) was shown in fig.5. From the fig. 5, it shows that the highest $\%$ of drug release $(86.22 \%)$ was obtained with the liposomal formulation having a ratio (1:1) of CH: PL90G.

The PT release from liposomal formulation is increased as the concentration of the PL90G was increased [from 1:0.25 (62.59\%) to $1: 1(86.22 \%)]$ and further increases to this ratio resulting into decline of release rate [from 1:2 (64.79\%) to $1: 3(60.38 \%)]$.

Comparing the cumulative amount (fig. 5) after $300 \mathrm{~min}$, the highest $\%$ drug release $(79.25 \%)$ and $(82.64 \%)$ was obtained with the liposomal formulation having a ratio (1:1) of $\mathrm{CH}$ : PL80H and $\mathrm{CH}$ : PL90H respectively. The PT release from liposomal formulation $(\mathrm{CH}$ : $\mathrm{PL80H}$ ) is increased as the concentration of the PL80H was increased [from 1:0.25 (58.11\%) to $1: 1(79.25 \%)$ ] and further increases to this ratio resulting into decline of release rate [from 1:2 $(62.45 \%)$ to $1: 3(53.71 \%)]$

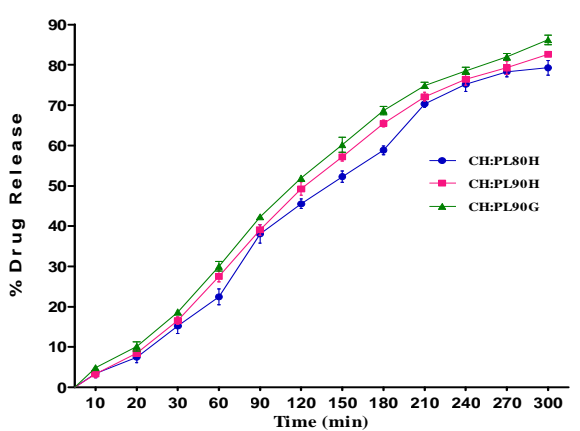

Fig. 5: \% In vitro drug release by PTL containing 1:1 ratio of cholesterol and phospholipid [CH: PL90G (1:1); CH: PL80H (1:1); CH: PL90H (1:1)] (results are expressed as mean, $n=3$ )

Same result was obtained in liposomal formulation (CH: PL90H) the PT release is increased as the concentration of the PL90H was increased [from 1:0.25 (60.69\%) to $1: 1(82.64 \%)$ ] and decrease release rate [from 1:2 (61.70\%) to $1: 3(57.23 \%)]$ further increases the ratio. It showed that the release rate of PT from PTL was found to be best when a ratio between cholesterol and phospholipids were (1:1) and also indicates higher penetration potential comparison to 
drug solution. Finally, the enhanced released rate of liposomes with ratio (1:1), can be elucidated that, the amphiphilic nature of phospholipids enhances the wetting of liposomes in dissolution media, which in term prolong the release rate of ratio(1:1), compared to other as suggested by Utreja (34).

\section{Hemolytic toxicity assay (HTA)}

The effect of PTL formulation on hemolysis of RBCs was shown in fig.6. The $\mathrm{CH}$ and phospholipids ratio (1:1) showed the best hemolytic activity. The hemolytic toxicity with $\mathrm{CH}$ : PL80H (1:1) was found to be $6.77 \%$. In the case of CH: PL90H (1:1), the hemolytic toxicity was found to be $4.44 \%$.

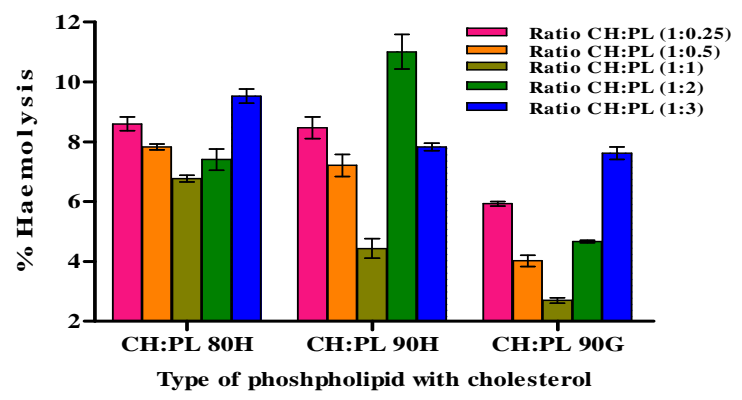

Fig. 6: Percentage (\%) hemolysis of RBCs by PTL containing a different ratio of cholesterol and phospholipid (results are expressed as mean, $n=3$ )

In contrast to this, the least hemolytic toxicity was found to be $2.70 \%$, when CH: PL90G ratio was (1:1). Similarly, the significant result of lower toxicity was found to be for PT solid dispersion in comparison to commercial Taxol formulation [38]. Based on above discussion, it can be concluded that the $11: 1)$ ratio of $\mathrm{CH}$ : PL90G might be responsible for the excellent hemolytic activity. Significantly it happens due to its composition. These vesicles are made from biocompatible phospholipids as a major constituent.

\section{CONCLUSION}

The present work reveals the excellent effect of phospholipids on PTL. The PTL's were prepared by film hydration method, with the incorporation of various phospholipids. The PTL prepared with $\mathrm{CH}$ : PL90G ratio (1:1) was found to be optimized one. The EE was found to be $86.67 \%$. Whereas, particle size with this ratio showed to be uniform size distribution. The in vitro release rate in phosphate buffer saline (PBS, pH 7.4) was also found to be enhanced. The PTL formulation showed a least hemolytic toxicity. Hence this formulation might be accountable for a better alternative of existing PT dosage form.

\section{ACKNOWLEDGEMENT}

The authors wish to express their thanks and gratitude to lipoid $\mathrm{GmbH}$, Germany for providing phospholipids as a gift sample and MAC-CHEM Products (India) Pvt. Ltd., Thane, India for providing paclitaxel as a gift sample for this study, also thankful to University Dept. of Pharmaceutical Sciences, RTM Nagpur University, Nagpur for providing necessary facilities for this work. Thanks are also attributable to SKB College of Pharmacy, Kamptee, Nagpur for everything they have done for the completion of this study.

\section{AUTHORS CONTRIBUTION}

This work was carried out in collaboration between all the four authors in the concept and design of the work, collection, assembly, analysis and interpretation of data, writing, critical revision and approval of the final manuscript.

\section{CONFLICT OF INTERESTS}

All authors have none to declare

\section{REFERENCES}

1. Brasili E, Filho VC. Metabolomics of cancer cell cultures to assess the effects of dietary phytochemicals. Crit Rev Food Sci Nutr 2017;57:1328-39.

2. Hanahan D, Weinberg RA. Hallmarks of cancer: the next generation. Cell 2011;144:646-74.

3. Cairns RA, Mak TW. The current state of cancer metabolism. Nat Rev Cancer 2016;16:613-4.

4. Liu QS, Deng R, Yan QF, Cheng L, Luo Y, Li K, et al. Novel betatubulin-immobilized nanoparticles affinity material for screening $\beta$-tubulin inhibitors from a complex mixture. ACS Appl Mater Interfaces 2017;9:5725-32.

5. Louage B, De Wever O, Hennink WE, De Geest BG. Developments and future clinical outlook of taxane nanomedicines. J. Controlled Release 2017;253:137-52.

6. Schiff PB, Horwitz SB. Taxol stabilize microtubules in mouse fibroblast cells. Proc Natl Acad Sci USA 1980;77:1561-5.

7. Ye J, Liu Y, Xia X, Meng L, Dong W, Wang R, et al. Improved safety and efficacy of a lipid emulsion loaded with a paclitaxelcholesterol complex for the treatment of breast tumors. Oncol Rep 2016;36:399-409.

8. Kampan NC, Madondo MT, McNally OM, Quinn M, Plebanski M. Paclitaxel and its evolving role in the management of ovarian cancer. BioMed Res Int 2015;2015:1-21. http://dx.doi.org/10.1155/2015/413076

9. Wang L, Yu RS, Yang WL, Luan SJ, Qin BK, Pang XB, et al. Effects of paclitaxel loaded-drug micelles on cell proliferation and apoptosis of human lung cancer A549 cells. Acta Pharm Sin 2015;50:1240-5.

10. Lemstrova R, Melichar B, Mohelnikova-Duchonova B. Therapeutic potential of taxanes in the treatment of metastatic pancreatic cancer. Cancer Chemother Pharmacol 2016;78:1101-11.

11. Mullins DW, Burger CJ, Elgert KD. Paclitaxel enhances macrophage IL-12 production in tumor-bearing hosts through nitric oxide. J Immunol 1999;162:6811-8.

12. Glass-Marmor L, Beitner R. Taxol (paclitaxel) induces a detachment of phosphofructokinase from cytoskeleton of melanoma cells and decreases the levels of glucose 1, 6bisphosphate, fructose 1, 6-bisphosphate and ATP. Eur J Pharmacol 1999;370:195-9.

13. Thanki K, Gangwal RP, Sangamwar AT, Jain S. Oral delivery of anticancer drugs: challenges and opportunities. J Controlled Release 2013;170:15-40.

14. Backman JT, Filppula AM, Niemi M, Neuvonen PJ. Role of cytochrome P450 2C8 in drug metabolism and interactions. Pharmacol Rev 2016;68:168-241.

15. Li J, Tang J, Li Y, Yu J, Zhang B, Yu C. Pharmacokinetic profile of paclitaxel in the plasma, lung, and diaphragm following intravenous or intrapleural administration in rats. Thorac Cancer 2015;6:43-8.

16. Webster LK, Woodcock DM, Rischin D, Millward MJ. Review: cremophor: pharmacological activity of an" inert" solubiliser. J Oncol Pharm Pract 1997;3:186-92.

17. Cragun JM, Baggs JH, Rollins C, Chambers SK. Case report hypersensitivity reaction to parenteral nutrition after severe hypersensitivity reaction to paclitaxel. Am J Clin Exp Obstet Gynecol 2013;1:69-75.

18. Singla AK, Garg A, Aggarwal D. Paclitaxel and its formulations. Int J Pharm 2002;235:179-92.

19. Moes J, Koolen S, Huitema A, Schellens J, Beijnen J, Nuijen B. Development of an oral solid dispersion formulation for use in low-dose metronomic chemotherapy of paclitaxel. Eur J Pharm Biopharm 2013;83:87-94.

20. Sandhu PS, Beg S, Mehta F, Singh B, Trivedi P. Novel dietary lipid-based self-nanoemulsifying drug delivery systems of paclitaxel with p-gp inhibitor: implications on cytotoxicity and biopharmaceutical performance. Expert Opin Drug Delivery 2015;12:1809-22.

21. Li J, Wang F, Sun D, Wang R. A review of the ligands and related targeting strategies for active targeting of paclitaxel to tumours. J Drug Target 2016;24:590-602. 
22. Xu J, Zhang X, Chen $Y$, Huang $Y$, Wang $P$, Wei $Y$, et al. Improved micellar formulation for enhanced delivery for paclitaxel. Mol Pharm 2016;14:31-41.

23. Bonde S, Nair S. Advances in liposomal drug delivery system: fascinating types and potential applications. Int J Appl Pharm 2017;9:1-7.

24. Li J, Huang P, Chang L, Long X, Dong A, Liu J, et al. Tumor targeting and $\mathrm{pH}$-responsive polyelectrolyte complex nanoparticles based on hyaluronic acid-paclitaxel conjugates and chitosan for oral delivery of paclitaxel. Macromol Res 2013;21:1331-7.

25. Teow HM, Zhou Z, Najlah M, Yusof SR, Abbott NJ, D'Emanuele A. Delivery of paclitaxel across cellular barriers using a dendrimer-based nanocarrier. Int J Pharm 2013;441:701-11.

26. Al-Najjar BY, Hussain SA. Chitosan microspheres for the delivery of chemotherapeutic agents: paclitaxel as a model. Asian J Pharm Clin Res 2017;10:1-5.

27. Kulkarni PR, Yadav JD, Vaidya KA. Liposomes: a novel drug delivery system. Int J Curr Pharm Res 2011;3:10-8.

28. Zhang W, Wang G, Falconer JR, Baguley BC, Shaw JP, Liu J, et al. Strategies to maximize liposomal drug loading for a poorly water-soluble anticancer drug. Pharm Res 2015;32:1451-61.

29. Zhang H, Gong W, Wang ZY, Yuan SJ, Xie XY, Yang YF, et al. Preparation, characterization, and pharmacodynamics of thermosensitive liposomes containing docetaxel. J Pharm Sci 2014;103:2177-83.

30. Bhatia A, Singh B, Raza K, Shukla A, Amarji B, Katare OP. Tamoxifen-loaded novel liposomal formulations: evaluation of anticancer activity on DMBA-TPA induced mouse skin carcinogenesis. J Drug Target 2012;20:544-50.
31. Parikh RS, Patel BK. Formulation development and evaluation of temozolomide loaded hydrogenated soya phosphatidylcholine liposomes for the treatment of brain cancer. Asian J Pharm Clin Res 2016;9:340-3.

32. Dua JS, Rana AC, Bhandari AK. Liposome: methods of preparation and applications. Int J Pharm Stud Res 2012; 3:14-20.

33. Yang T, Cui FD, Choi MK, Lin H, Chung SJ, Shim CK, et al. Liposome formulation of paclitaxel with enhanced solubility and stability. Drug Delivery 2007;14:301-8.

34. Utreja P, Jain S, Tiwary AK. Localized delivery of paclitaxel using elastic liposomes: Formulation development and evaluation. Drug Delivery 2011;18:367-76.

35. Reed KW, Yalkowsky SH. Lysis of human red blood cells in the presence of various cosolvents. II. The effect of differing $\mathrm{NaCI}$ concentrations. PDA J Pharm Sci Technol 1986;40:88-94.

36. Kan P, Tsao CW, Wang AJ, Su WC, Liang HF. A liposomal formulation able to incorporate a high content of Paclitaxel and exert promising anticancer effect. J Drug Delivery 2010:1-9. http://dx.doi.org/10.1155/2011/629234

37. Nava G, Pinon E, Mendoza L, Mendoza N, Quintanar D, Ganem A. Formulation and in vitro, ex vivo and in vivo evaluation of elastic liposomes for transdermal delivery of ketorolac tromethamine. Pharmaceutics 2011;3:954-70.

38. Shanmugam S, Park JH, Chi SC, Yong CS, Choi HG, Woo JS. Physicochemical stability, pharmacokinetic, and biodistribution evaluation of paclitaxel solid dispersion prepared using supercritical antisolvent process. Drug Dev Ind Pharm 2011;37:628-37. 